\title{
PAPER
}

Cite this: RSC Adv., 2013, 3, 20324

Received 25th July 2013

Accepted 19th August 2013

DOI: $10.1039 / \mathrm{c} 3 \mathrm{ra} 43909 \mathrm{~g}$

www.rsc.org/advances

\section{Single step synthesis of metallic nanoparticles using dihydroxyl functionalized ionic liquids as reductive agent $\uparrow$}

\author{
Walid Darwich, ${ }^{a}$ Christian Gedig, ${ }^{\text {b }}$ Hassan Srour, ${ }^{\text {a Catherine C. Santini }}{ }^{\star a}$ \\ and Martin H. G. Prechtl*b
}

In the last few years, ionic liquids (ILs) have revealed their broad versatility for application towards the synthesis of shape and size controlled nanoscale metal catalysts, respectively metal(0) nanoparticles (MNPs) in the absence of additive ligand. ILs play the role of solvent and ligand. In our work, we depict the synthesis of M-NPs ( $\mathrm{M}=\mathrm{Cu}, \mathrm{Ag}, \mathrm{Ni}, \mathrm{Ru})$ using dihydroxyl functionalized imidazolium ILs 1-(2,3dihydroxypropyl)-2,3-dimethylimidazolium bis(trifluoromethanesulfonimide) $\quad\left[C_{1} C_{1}(E G) I m\right]\left[N T f_{2}\right]$ as solvent, stabilizer and reductive agent simultaneously. In this IL the formation of stable dispersion of NPs from silver and copper salts in the absence of any reducing agent has been observed. The comparison of the ${ }^{13} \mathrm{C}-\mathrm{NMR}$, and IR data of pure IL and IL-NP (Cu and Ag) suspensions proved the oxidation of the hydroxyl group to a carbonyl group, confirming that the dihydroxyl function of the IL acted as the reducing agent. This oxido-reduction depends on the nature of the metal. No reaction occurred with $\mathrm{Ni}^{\prime \prime}$ and $\mathrm{Ru}^{0}$ precursors, and with $\mathrm{Ru}^{\prime \prime}$ and $\mathrm{Ni}^{0}$ salts the formation of M-NPs is due to the activation of the acidic protons on the imidazolium ring. The Ru-NPs were then further evaluated for selective partial hydrogenation, here we observed good selectivities for $\alpha, \beta$-unsaturated compounds such as cyclohexenone and cinnamic aldehyde, which can be converted exclusively into the unsaturated alcohols or saturated alcohols.

\section{Introduction}

The progress in the comprehension of metallic nanoparticles (NPs) is a central aspect due to their great potential in the development of new and innovative materials for applications in areas such as catalysis or microelectronics. ${ }^{\mathbf{1 - 1 1}}$ Their small sizes, generally reported between 1 and $100 \mathrm{~nm}$, lead to unique physico-chemical properties between the bulk and molecular states, which vary greatly with small changes in NP size. For example, the catalytic properties of NPs are largely determined by the energy of the surface atoms, in turn controlled by the number of neighbouring atoms, dictated by their size, as well as the presence and nature of ligands or supports. ${ }^{12-16}$ Particles less than $10 \mathrm{~nm}$ in diameter are particularly interesting in catalysis, due to their high surface to volume ratio, and are also

\footnotetext{
${ }^{a}$ Université de Lyon, Institut de Chimie de Lyon, UMR 5265 CNRS-Université de Lyon 1-ESCPE Lyon, LC2P2, Equipe Chimie Organométallique de Surface, ESCPE 43 Boulevard du 11 Novembre 1918, F-69616 Villeurbanne, France. E-mail: catherine. santini@univ-lyon1.fr; Fax: +33 (0)472431795; Tel: +33 (0)472431810

${ }^{b}$ University of Cologne, Institute of Inorganic Chemistry - Research Group Catalysis, Greinstr. 6, D-50939 Köln, Germany. E-mail: martin.prechtl@uni-koeln.de; Fax: +49-221-470-1788; Tel: +49-221-470-1981

$\uparrow$ Electronic supplementary information (ESI) available: Additional spectral data. See DOI: 10.1039/c3ra43909g
}

greatly influenced by the aforementioned size-effect. ${ }^{17,18}$ To prevent aggregation, NPs must be stabilized by the use of capping agents such as (water-soluble) polymers, quaternary ammonium salts, surfactants, ligands or polyoxoanions, providing electronic and/or steric protection. ${ }^{\mathbf{1 9 , 2 0}}$ In this context, ionic liquids (ILs), defined as low temperature molten salts, have emerged as one of the most important and the most investigated media for the synthesis of metal NPs. ${ }^{21-24}$ Moreover, an advantage of using ILs is that stabilizing additives such as ligands, polymers and supports are not required. ${ }^{23}$ The soluble transition-metal NPs are in situ generated in ILs mainly from the following routes (a) simple reduction of $\mathbf{M}^{(n+)}$ salts, (b) decomposition of the organometallic complexes in the formal zero oxidation state, (c) bombardment of bulk metal precursors with deposition onto the ILs and (d) phase transfer of pre-formed NPs in water or organic solvents to the IL (Scheme 1). ${ }^{23}$

In general, appropriate metal complexes or metal salts are dispersed/dissolved in the ILs and subsequently reduced to the corresponding M-NPs, in the ubiquitous presences such as molecular dihydrogen gas, ${ }^{25}$ ethylene glycol, ${ }^{26}$ ascorbic acid, ${ }^{27}$ hydrazine,$^{28}$ and disulfide. ${ }^{29}$ In some cases, the IL has been claimed to be the reducing agent. ${ }^{30-32}$ However, in certain cases, an aqueous solution of ILs was used. For instance, the formation of $\mathrm{Au}^{0}$ microprisms in 1-butyl-3-methylimidazolium 


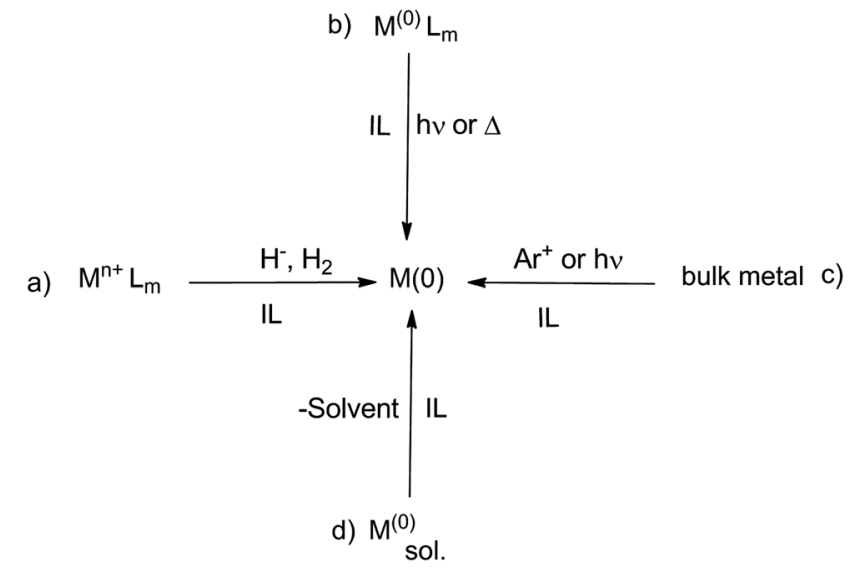

Scheme 1 General methods used to prepare metal NPs in ILs.

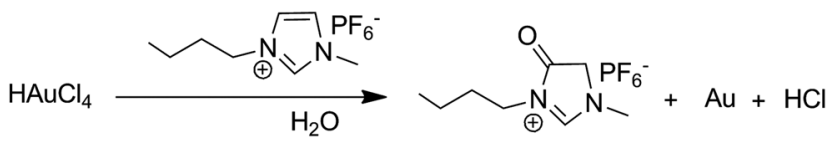

Scheme 2 The formation of $\mathrm{Au}^{0}$ microprisms in 1-butyl-3-methylimidazolium hexafluorophosphate in the presence of water. ${ }^{30}$

hexafluorophosphate in the presence of water has been explained by an oxido-reduction reaction consuming the IL (Scheme 2) and yielding $\left[\mathrm{Cl}^{-}\right]$anions in the media.

In water, using halide salts of mono and di-hydroxyl ILs as surfactants, a suspension of narrow size $\mathrm{Ag}^{0}$-NPs (mean size 2 or $4 \mathrm{~nm}$ following the IL) stabilized by the hydroxyl groups has been obtained using $\mathrm{AgNO}_{3}$ as metal source (Scheme 3). ${ }^{31}$ The oxidation of the $\mathrm{OH}$-group to the corresponding aldehyde during the reduction of $\mathrm{Ag}^{\mathrm{I}}$ into $\mathrm{Ag}^{0}$ has been evidenced by IR spectroscopy.

Pointing out that the particle size control can also be influenced by dissolved halides, especially in aqueous solutions of ILs. For instance, $\left[\mathrm{Cl}^{-}\right]$anions and water may coordinate onto the metal surface, acting as extra-stabilizers, but also influencing the nanoparticle properties (optical, magnetic and catalytic)..$^{33}$

Contrary, in our previous studies using neat anhydrous alkyl imidazolium IL like $\left[\mathrm{C}_{1} \mathrm{C}_{n} \operatorname{ImNTf}_{2}\right](n=4$ and 6) as reaction media under argon, the formation of $\mathrm{Ru}^{0}-\mathrm{NPs}$ and $\mathrm{Ni}^{\circ}$-NPs by reduction of bis(2-methylallyl)(1,5-cyclooctadiene) ruthenium $\left[\mathrm{Ru}^{\mathrm{II}}(\mathrm{Me}-\text {-allyl })_{2}(\mathrm{COD})\right]$, respectively auto-decomposition of bis $\left(\eta^{4}-1,5\right.$-cyclooctadiene)nickel $\quad\left[\mathrm{Ni}^{0}(\mathrm{COD})_{2}\right]$ have been observed. ${ }^{32}$ These methods afforded small-sized and monodispersed Ru-NPs (1-3 nm; mean diameter: $2.0 \pm 0.3 \mathrm{~nm}$ ) and for Ni-NPs a broader size distribution (2-12 $\mathrm{nm}$; mean diameter: $7.0 \pm 2.0 \mathrm{~nm}$ and higher agglomeration).

Generally, the NP formation in solution depends on three key factors (i) the solvent medium, (ii) the reducing agent, and (iii)

$$
2 \mathrm{Ag}^{+} \stackrel{+}{-\left(\mathrm{R}-\mathrm{Im}-\mathrm{CH}_{2} \mathrm{CH}_{2} \mathrm{OH}\right) \mathrm{X}} \underset{-\left(\mathrm{R}-\mathrm{Im}-\mathrm{CH}_{2} \mathrm{CHO}\right) \mathrm{X}}{\longrightarrow}-2 \mathrm{Ag}^{0}+2 \mathrm{H}^{+}
$$

Scheme 3 Preparation of Ag-NPs using the hydroxyl group linked to the imidazolium cation as reducing agents. ${ }^{31}$ the stabilizer. ILs are largely depicted as solvent and stabilizer for NPs and are scarcely used as a reducing agent. In this work, we report, that an anhydrous dihydroxyl functionalized imidazolium IL, namely 1-(2,3-dihydroxypropyl)-2,3-dimethylimidazolium bis(trifluoromethanesulfonimide) $\left(\left[\mathrm{C}_{1} \mathrm{C}_{1}(\mathrm{EG}) \mathrm{Im}\right]\left[\mathrm{NTf}_{2}\right]\right)$ based on a building block derived from abundant biomass namely glycerine, conjuncts these four roles: solvent, stabilizer, surface modifier and reductant in the in situ synthesis of NPs.

The role as metal nanoparticle surface modifier we have investigated in particular regarding the partial hydrogenation of organic substrates with ruthenium nanoparticles. In previous works we reported that functional groups in the moieties of ionic liquid side-chain show significant influence towards the selectivity while using Ru-NPs as hydrogenation catalyst for arene versus nitrile entities. ${ }^{38,39}$ There, we showed that nitriles completely suppress the usual occurring arene hydrogenation.

\section{Results and discussion}

In order to prove the specific reactivity of $\left[\mathrm{C}_{1} \mathrm{C}_{1}(\mathrm{EG}) \mathrm{Im}\right]\left[\mathrm{NTf}_{2}\right]$, the thermal stability of all chosen metal precursors (Table 1) in this IL under argon have also been studied in $\left[\mathrm{C}_{1} \mathrm{C}_{4} \mathrm{Im}\right]\left[\mathrm{NTf}_{2}\right]$. Each precursor has been successively heated in IL under argon until a colour change was observed (Scheme 4).

Experiments with $\mathrm{AgNO}_{3}$, CuMes, anhydrous $\mathrm{CuSO}_{4}$ and $\mathrm{Ru}(\mathrm{COD})(\mathrm{COT})$ in $\left[\mathrm{C}_{1} \mathrm{C}_{4} \mathrm{Im}\right]\left[\mathrm{NTf}_{2}\right]$ showed no reaction. In contrast $\mathrm{Ru}(\mathrm{Me}-\mathrm{allyl})_{2}(\mathrm{COD})$ and $\mathrm{Ni}(\mathrm{COD})_{2}$ already decompose at low temperature. ${ }^{32}$ In $\left[\mathrm{C}_{1} \mathrm{C}_{1}(\mathrm{EG}) \mathrm{Im}\right]\left[\mathrm{NTf}_{2}\right]$ no reactions were observed with anhydrous $\mathrm{CuSO}_{4}, \mathrm{Ru}(\mathrm{COD})(\mathrm{COT})$ and $\mathrm{Ni}\left(\mathrm{NTf}_{2}\right)_{2}$ after stirring overnight at $130{ }^{\circ} \mathrm{C}$, neither colour changes of the solutions were visible, nor NPs could be located in TEM images (Table 1, entries $1,3,5)$. In $\left[\mathrm{C}_{1} \mathrm{C}_{1}(\mathrm{EG}) \mathrm{Im}\right]\left[\mathrm{NTf}_{2}\right], \mathrm{Ru}(\mathrm{Me}-\text { allyl })_{2^{-}}$ (COD), $\mathrm{Ni}(\mathrm{COD})_{2}$ and $\mathrm{AgNO}_{3}$ led to NPs at $90{ }^{\circ} \mathrm{C}$ in 1,2 and $4 \mathrm{~h}$, respectively (Table 1 , entries $2,4,6$ ). The formation of Cu-NPs in $\left[\mathrm{C}_{1} \mathrm{C}_{1}(\mathrm{EG}) \mathrm{Im}\right]\left[\mathrm{NTf}_{2}\right]$ from mesityl copper (CuMes) was observed after $12 \mathrm{~h}$ at $130{ }^{\circ} \mathrm{C}$ (Table 1 , entry 7 ). All results with the corresponding mean diameters are listed in Table 1.

\section{Silver nanoparticle synthesis}

Silver nitrate is reduced in aqueous mono- and dihydroxyl functionalized imidazolium ionic liquid within in $2 \mathrm{~h}$ at $60^{\circ} \mathrm{C}$, the generated Ag-NPs show sizes of 4-8 $\mathrm{nm}$ and 2-4 $\mathrm{nm}$, respectively. ${ }^{31}$ The presence of dihydroxyl functional group

Table 1 Experimental conditions and the mean sizes of the M-NPs formed in $\left[\mathrm{C}_{1} \mathrm{C}_{1}(\mathrm{EG}) \mathrm{Im}\right]\left[\mathrm{NTf}_{2}\right]$ under argon

\begin{tabular}{llll}
\hline Entry & Metal source $^{a}[\mathrm{M}]$ & $t[\mathrm{~h}] / T\left[{ }^{\circ} \mathrm{C}\right]$ & NP size $(\mathrm{nm})$ \\
\hline 1 & $\mathrm{CuSO}_{4}$ & $12 \mathrm{~h} / 130{ }^{\circ} \mathrm{C}$ & n.r. \\
2 & $\mathrm{AgNO}_{3}$ & $4 \mathrm{~h} / 90{ }^{\circ} \mathrm{C}$ & $4.7 \pm 0.8 \mathrm{~nm}$ \\
3 & $\mathrm{Ru}(\mathrm{COD})(\mathrm{COT})$ & $12 \mathrm{~h} / 130{ }^{\circ} \mathrm{C}$ & n.r. \\
4 & $\mathrm{Ni}(\mathrm{COD})_{2}$ & $2 \mathrm{~h} / 90{ }^{\circ} \mathrm{C}$ & $3.5 \pm 0.5 \mathrm{~nm}$ \\
5 & $\mathrm{Ni}(\mathrm{NTf})_{2}$ & $12 \mathrm{~h} / 130{ }^{\circ} \mathrm{C}$ & n.r. \\
6 & $\mathrm{Ru}(\mathrm{COD})(\mathrm{Me}-\text { allyl })_{2}$ & $1 \mathrm{~h} / 90{ }^{\circ} \mathrm{C}$ & $6.9 \pm 1.3 \mathrm{~nm}$ \\
7 & $\mathrm{CuMes}$ & $12 \mathrm{~h} / 130{ }^{\circ} \mathrm{C}$ & $5.7 \pm 0.8 \mathrm{~nm}$
\end{tabular}

${ }^{a}[\mathrm{C}] 0.01 \mathrm{M}$ of metal precursor in $1.5 \mathrm{~mL}$ of $\left[\mathrm{C}_{1} \mathrm{C}_{1}(\mathrm{EG}) \operatorname{Im}\right]\left[\mathrm{NTf}_{2}\right]$, n.r. ${ }^{*}=$ no reaction. 


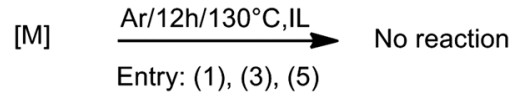

[M]

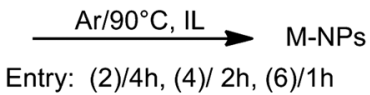

[M]

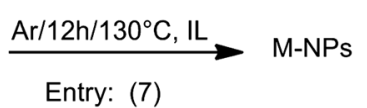

Scheme 4 General overview for the decomposition/reduction of metal precursors in $\left[C_{1} C_{1}(E G) I m\right]\left[N T f_{2}\right]$ at the applied reaction temperatures and durations (refer Table 1).
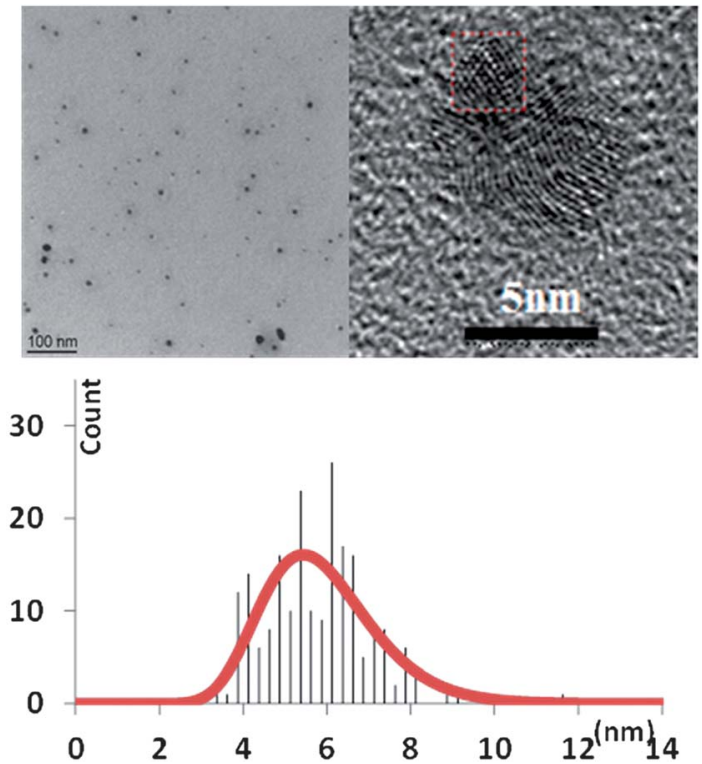

Fig. 1 TEM and HRTEM images of Ag-NPs in $\left[C_{1} C_{1}(E G) I m\right]\left[N T f_{2}\right]$ and their particles size distribution.

Table 2 Theoretical ${ }^{a}$ (JCPD 04-016-1388) and experimental interplanar distances $(\mathrm{nm})$, and angles $\left({ }^{\circ}\right)$ for Ag-NPs

\begin{tabular}{lrllcc}
\hline Spot & $h k l$ & $d(\exp ), \mathrm{nm}$ & $d$ (theo), nm & Angle (exp) & Angle (theo) \\
\hline 1 & 101 & 0.2295 & 0.224270 & 0 & 0 \\
2 & 011 & 0.2466 & 0.224270 & 50.29 & 52.44 \\
3 & -110 & 0.2529 & 0.224270 & 119.67 & 116.22
\end{tabular}

${ }^{a}$ M. I. Novgorodova, A. Gorshkov and A. V. Mokhov, Zap. Vses. Mineral. O-va., 1979, 108, 552-563; H. Brodowsky, A. Fruma, H. Sagunski and H. J. Schaller, Z. Metallkd., 1982, 73, 354 for the crystallographic data.

induces probably a higher size control. In our experimental conditions, (Table 1 , entry $2: 2 \mathrm{~h}$ at $90{ }^{\circ} \mathrm{C}$ in neat $\left[\mathrm{C}_{1} \mathrm{C}_{1}(\mathrm{EG}) \mathrm{Im}\right]$ $\left.\left[\mathrm{NTf}_{2}\right]\right)$ the Ag-NP were formed with a mean size about $4.7 \pm 0.8$ nm (Fig. 1) for $90 \%$ of the NP population and at ca. $10 \mathrm{~nm}$ for $10 \%$. The structure of individual particles was investigated using HRTEM, Fig. 1. The interplanar distance measured from this micrograph is $0.2295 \mathrm{~nm}$ (Table 2), corresponding to the (101) interplanar distance of hexagonal metallic Ag.

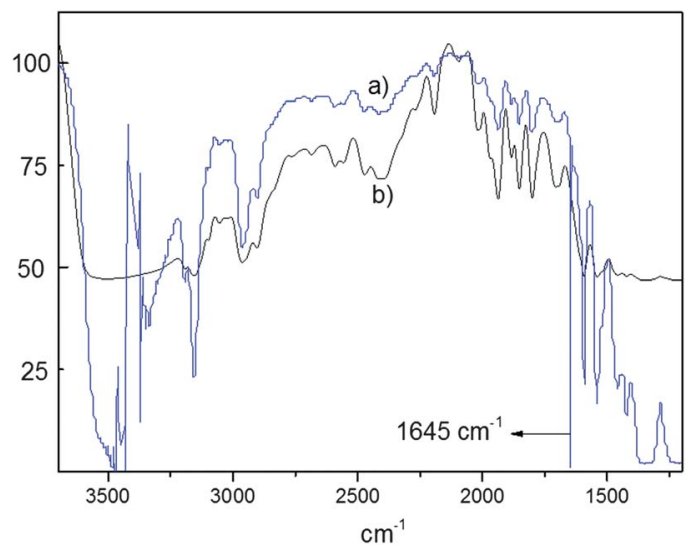

Fig. 2 FT-IR spectra of suspension of (a) Ag-NPs in $\left[C_{1} C_{1}(E G) I m\right]\left[N T f_{2}\right]$ after reaction (b) pure $\left[C_{1} C_{1}(E G) I m\right]\left[N T f_{2}\right]$.

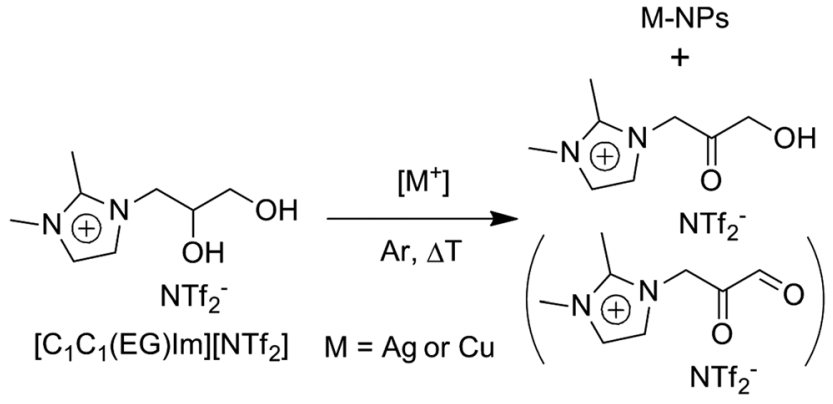

Scheme 5 Proposed oxido-reduction mechanism.

FT-IR spectroscopy was used to investigate the interactions between different species and changes in chemical composition of the mixtures. Fig. 2 shows the FT-IR spectra of pure $\left[\mathrm{C}_{1} \mathrm{C}_{1}(\mathrm{EG})\right.$ $\mathrm{Im}]\left[\mathrm{NTf}_{2}\right](\mathrm{b})$, and of the reaction media after the formation of Ag-NPs (a). In the IR spectra of the neat $\left[\mathrm{C}_{1} \mathrm{C}_{1}(\mathrm{EG}) \mathrm{Im}\right]\left[\mathrm{NTf}_{2}\right]$, a broad peak of $(3220-3720) \mathrm{cm}^{-1}$ centred at $3504 \mathrm{~cm}^{-1}$ and peaks at $1530 \mathrm{~cm}^{-1}$ and $1590 \mathrm{~cm}^{-1}$ are related to the hydroxyl function. In the IR spectra of the Ag-NP suspensions, all these bands are less wide and changed from $\left(3220-3720 \mathrm{~cm}^{-1}\right)$ to (3500-3600 $\mathrm{cm}^{-1}$ ) and are centred at $3525 \mathrm{~cm}^{-1}$ and a new peak is observed at $1645 \mathrm{~cm}^{-1}$ assigned to the vibration of conjugated carbonyl groups resulting from the oxidation of the OH-group, during the reduction of metal ions (Fig. 2 and Scheme 5). The formation of this carbonyl function is also confirmed by the peak at $205 \mathrm{ppm}$ assigned to a $\delta_{\mathrm{C}=\mathrm{O}}$ in the ${ }^{13} \mathrm{C}$ NMR spectra of the Ag-NP suspension (Fig. 3).

\section{Copper nanoparticle synthesis}

The decomposition of mesityl copper (CuMes) in [ $\left.\mathrm{C}_{1} \mathrm{C}_{1}(\mathrm{EG}) \mathrm{Im}\right]$ $\left[\mathrm{NTf}_{2}\right]$ at $130{ }^{\circ} \mathrm{C}$ within $12 \mathrm{~h}$ yielded well dispersed $\mathrm{Cu}$-NPs with a mean size around $5.7 \mathrm{~nm}$ (Fig. 4). While, CuMes in $\left[\mathrm{C}_{1} \mathrm{C}_{4} \mathrm{Im}\right]-$ [ $\mathrm{NTf}_{2}$ ] under $0.9 \mathrm{MPa}$ of $\mathrm{H}_{2}$ resulted in $\mathrm{Cu}$-NPs with a size distribution centred around $6.4 \mathrm{~nm}$ at $30^{\circ} \mathrm{C}$, respectively $4.5 \mathrm{~nm}$ at $100{ }^{\circ} \mathrm{C}$ reaction temperatures. ${ }^{4}$

Note that no reaction occurs with $\mathrm{CuSO}_{4}$ in $\left[\mathrm{C}_{1} \mathrm{C}_{1}(\mathrm{EG}) \mathrm{Im}\right]-$ $\left[\mathrm{NTf}_{2}\right]$ whatever the experimental conditions are. Contrarily, 

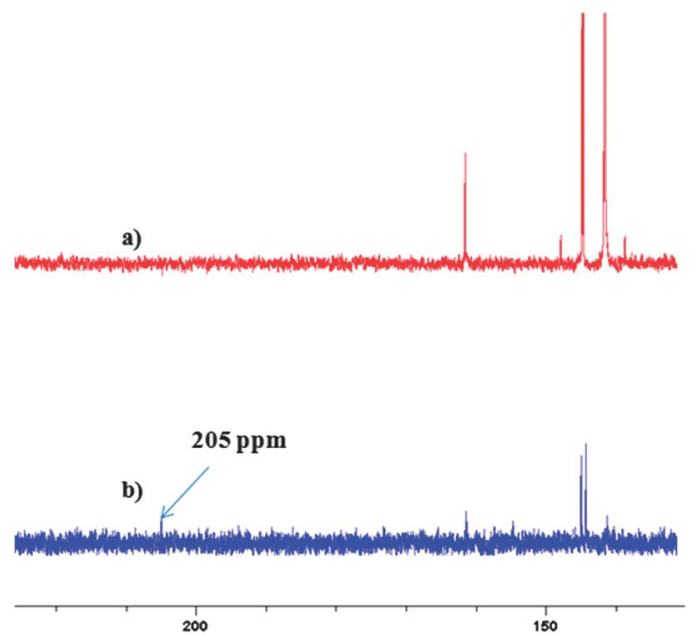

Fig. $3{ }^{13} \mathrm{C}$ NMR spectra (a) pure $\left[C_{1} C_{1}(E G) I m\right]\left[N T f_{2}\right] ;$ (b) suspension of Ag-NPs in $\left[C_{1} C_{1}(E G) \mid m\right]\left[N T f_{2}\right]$.

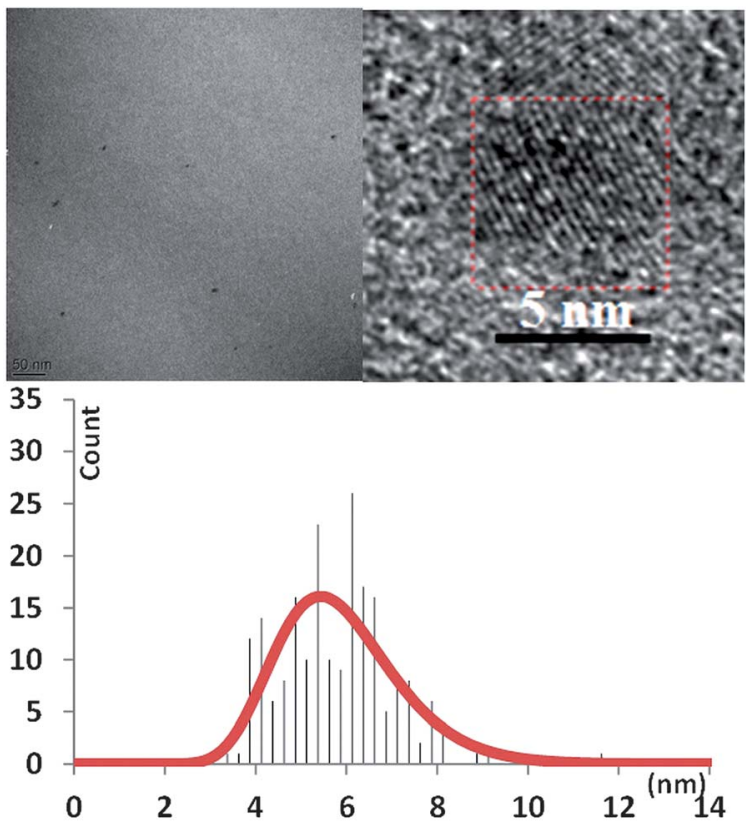

Fig. 4 TEM and HRTEM images of Cu-NPs in $\left[C_{1} C_{1}(E G) I m\right]\left[N T f_{2}\right]$ and their particles size distribution.

Cu-NPs are formed using this salt in $\mathrm{C}_{1} \mathrm{C}_{4} \mathrm{ImBF}_{4}$ in the presence of hydrazine as a reducing agent and ethylene glycol playing the role as ligand. ${ }^{28}$ The comparison of the FT-IR spectra of the $\mathrm{Cu}-\mathrm{NP}$ suspension in $\left[\mathrm{C}_{1} \mathrm{C}_{1}(\mathrm{EG}) \mathrm{Im}\right]\left[\mathrm{NTf}_{2}\right]$ (Fig. S1a $\dagger$ ) and the pure $\left[\mathrm{C}_{1} \mathrm{C}_{1}(\mathrm{EG}) \mathrm{Im}\right]\left[\mathrm{NTf}_{2}\right]$ (Fig. S1b†) shows the presence of stretching peaks at $1645 \mathrm{~cm}^{-1}$ corresponding to a carbonyl group vibration, similar to the Ag-NPs synthesis (see above).

With $\mathrm{AgNO}_{3}$ and CuMes an oxidation of one of the hydroxyl to carbonyl function was observed affording Ag-NPs and Cu-NPs, following the oxido-reduction mechanism depicted in Scheme 5 .

The interplanar distance measured from this micrograph is $0.2012 \mathrm{~nm}$ (Table 3), which coincides with the (111) interplanar distance of cubic metallic $\mathrm{Cu}$.
Table 3 Theoretical $^{a}$ (JCPD 04-001-3342) and experimental interplanar distances $(\mathrm{nm})$ and angles of Cu-NPs

\begin{tabular}{llllll}
\hline Spot & $h k l$ & $d(\exp ), \mathrm{nm}$ & $d$ (theo), nm & Angle (exp) & Angle (theo) \\
\hline 1 & 111 & 0.2012 & 0.2087240 & 0 & 0 \\
2 & 200 & 0.1753 & 0.1807600 & 90.11 & 90 \\
3 & 220 & 0.1344 & 0.1278170 & 42.90 & 45
\end{tabular}

${ }^{a}$ M. I. Novgorodova, A. Gorshkov and A. V. Mokhov, Zap. Vses. Mineral. O-va., 1979, 108, 552-563; H. Brodowsky, A. Fruma, H. Sagunski and H. J. Schaller, Z. Metallkd., 1982, 73, 354 for the crystallographic data.

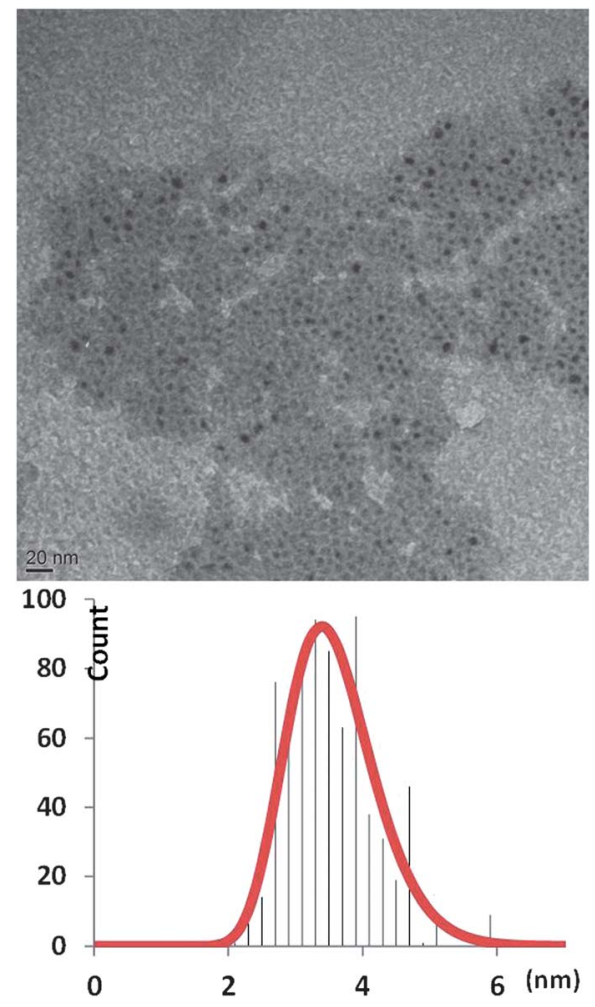

Fig. 5 TEM image of Ni-NPs in $\left[C_{1} C_{1}(E G) I m\right]\left[N T f_{2}\right]$ and particles size distribution.

\section{Nickel nanoparticle synthesis}

An auto-decomposition of the organometallic complex $\mathrm{Ni}(\mathrm{COD})_{2}$ is observed affording nickel nanoparticles Ni-NPs in neat $\left[\mathrm{C}_{1} \mathrm{C}_{4} \mathrm{Im}\right]\left[\mathrm{NTf}_{2}\right]$ at room temperature under argon. This occurs via a $\mathrm{C}-\mathrm{H}$ insertion at the acidic $\mathrm{C}_{2}$-position of the imidazolium ring and the formation of N-heterocyclic carbenes. ${ }^{32}$ To overcome this side reaction, we have used $\left[\mathrm{C}_{1} \mathrm{C}_{1}(\mathrm{EG}) \mathrm{Im}\right]-$ $\left[\mathrm{NTf}_{2}\right]$ substituted with a methyl group at the $\mathrm{C}_{2}$-position. When $\mathrm{Ni}(\mathrm{COD})_{2}$ was dissolved in $\left[\mathrm{C}_{1} \mathrm{C}_{1}(\mathrm{EG}) \mathrm{Im}\right]\left[\mathrm{NTf}_{2}\right]$ under argon, no reaction was observed at room temperature. At $90{ }^{\circ} \mathrm{C}$ after $2 \mathrm{~h}$, a homogeneous suspension of Ni-NPs was obtained with a narrow size distribution centred around $3.5 \pm 0.5 \mathrm{~nm}$ (Fig. 5).

The analysis of the resulting solution by gas chromatography showed as major product cycloocta-1,5-diene (1,5-COD), accompanied by its isomer cycloocta-1,3-diene (1,3-COD) and cyclooctene and traces of cyclooctane (Fig. S2 $\dagger$ ). The presence of large amount of 1,5-COD could be explained by a ligand exchange with a diol functionality. Following route A (Scheme 


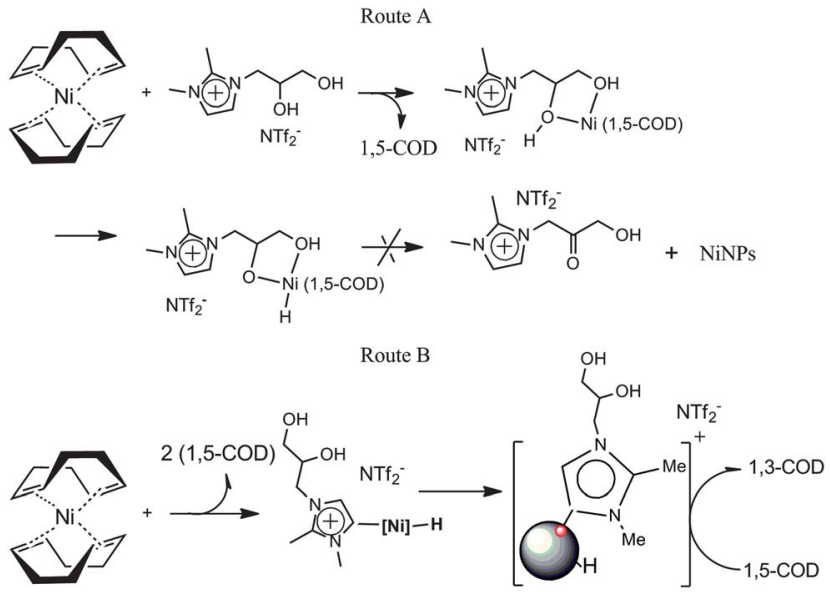

Scheme 6 Possible mechanism to explain the formation of Ni-NPs in $\left[C_{1} C_{1}(E G)\right.$ Im] $\left[\mathrm{NTf}_{2}\right]$. $^{32}$

6), the formation of $\mathrm{Ni}^{\mathrm{II}}-\mathrm{H}$ is necessary to explain the isomerization of 1,5-COD into 1,3-COD. But, $\mathrm{Ni}^{\mathrm{II}}$ salt is not reduced to $\mathrm{Ni}$-NPs, in this media, vide supra, thus route A (Scheme 6) could not explain the experimental results. Consequently the decomposition can only be explained by $\mathrm{C}-\mathrm{H}$ insertion at the less acidic $\mathrm{C}_{4}-\mathrm{H}, \mathrm{C}_{5}-\mathrm{H}$ positions of the imidazolium ring and generation of transitory non-classical NHC ligands; route B in Scheme $6 .^{32,34}$

\section{Ruthenium nanoparticle synthesis}

While $\mathrm{Ru}(\mathrm{COD})(\mathrm{COT})$ under $\mathrm{H}_{2}$ already at $0{ }^{\circ} \mathrm{C}$ readily affords Ru-NPs in any ILs; contrarily, in $\left[\mathrm{C}_{1} \mathrm{C}_{1}(\mathrm{EG}) \mathrm{Im}\right]\left[\mathrm{NTf}_{2}\right]$ under argon, as well in $\left[\mathrm{C}_{1} \mathrm{C}_{4} \mathrm{Im}\right]\left[\mathrm{NTf}_{2}\right]$ no Ru-NPs are observed.

In $\left[\mathrm{C}_{1} \mathrm{C}_{4} \mathrm{Im}\right]\left[\mathrm{NTf}_{2}\right], \mathrm{Ru}(\mathrm{Me} \text {-allyl })_{2}(\mathrm{COD})$ is readily decomposed at room temperature after prolonged reaction time (Scheme $\mathrm{S} 1 \dagger) .{ }^{32}$ In $\left[\mathrm{C}_{1} \mathrm{C}_{1}(\mathrm{EG}) \mathrm{Im}\right]\left[\mathrm{NTf}_{2}\right]$, Ru-NPs were formed at $90^{\circ} \mathrm{C}$ after $1 \mathrm{~h}$, leading to a broader size distribution $(6.9 \pm 1.3 \mathrm{~nm}$; Fig. 6 and $33 \dagger$ ). These NP could result from a decomposition as already reported, ${ }^{32}$ through an oxido-reductive reaction as observed with $\mathrm{Cu}$ and $\mathrm{Ag}$ precursors or by the attack on the two acidic protons $\mathrm{C}_{4}-\mathrm{H}, \mathrm{C}_{5}-\mathrm{H}$ as observed with $\mathrm{Ni}(\mathrm{COD})_{2}$. No difference was observed between the FT-IR and ${ }^{13} \mathrm{C}$ NMR spectra of the media before and after reaction (Fig. $\mathrm{S} 4 \dagger$ ).

The gas chromatogram of the reaction media was similar to the one obtained with $\mathrm{Ni}(\mathrm{COD})_{2}$ (Fig. S5 $\dagger$ ) due to ligand loss. Consequently, as for $\left[\mathrm{Ni}(\mathrm{COD})_{2}\right]$, the formation of M-NPs from $\left[\mathrm{Ru}(\mathrm{COD})(2-\text { methylallyl })_{2}\right]$, was probably due to the activation of the acidic protons on the imidazolium ring. ${ }^{32}$ However, in $\left[\mathrm{C}_{1} \mathrm{C}_{1}(\mathrm{EG}) \mathrm{Im}\right]\left[\mathrm{NTf}_{2}\right]$, the formation Ru-NPs differs to those previously reported in non-functionalized ILs such as $\left[\mathrm{C}_{1} \mathrm{C}_{4} \mathrm{Im}\right]$ $\left[\mathrm{NTf}_{2}\right]$ because contrary in $\left[\mathrm{C}_{1} \mathrm{C}_{1}(\mathrm{EG}) \mathrm{Im}\right]\left[\mathrm{NTf}_{2}\right]$ no imidazolium ring fragmentation was observed during the reaction of the ruthenium precursor with the IL. ${ }^{32}$

\section{Catalytic hydrogenation with ruthenium nanoparticles}

For further evaluation of the properties of the ruthenium nanoparticles we tested their catalytic activity for hydrogenation
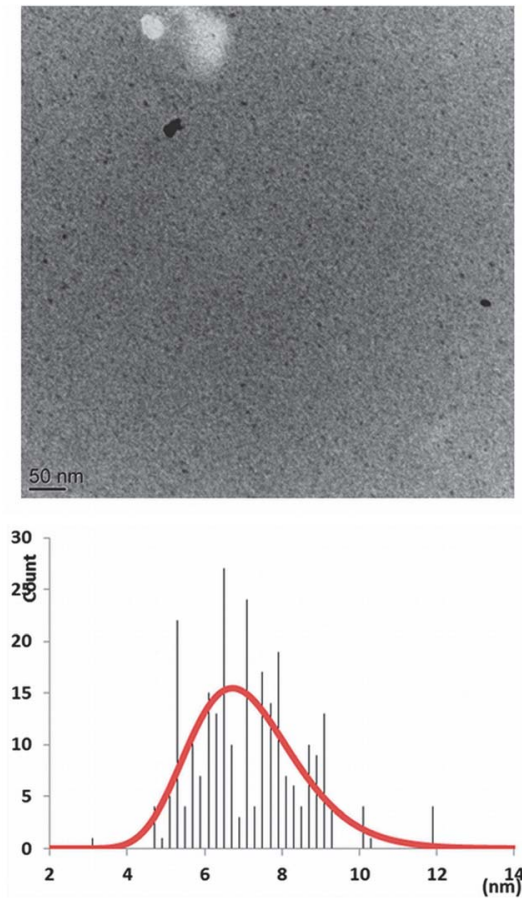

Fig. 6 TEM image of Ru-NPs in $\left[C_{1} C_{1}(E G) I m\right]\left[N T f_{2}\right]$ and particles size distribution.

Table 4 Hydrogenation of different substrates with Ru-NPs

\begin{tabular}{|c|c|c|c|c|c|c|}
\hline Entry & Substrate $^{a}$ & $\begin{array}{l}t \\
{[\mathrm{~h}]}\end{array}$ & $\begin{array}{l}p^{a} \\
\text { (bar) }\end{array}$ & $\begin{array}{l}\text { Conv. }^{b} \\
{[\%]}\end{array}$ & TON & $\begin{array}{l}\text { Product } \\
\text { selectivity }^{b}\end{array}$ \\
\hline 1 & Toluene $\mathbf{1}$ & 24 & 4 & 0 & 0 & - \\
\hline 2 & Toluene $\mathbf{1}$ & 24 & 40 & $>99^{c}$ & $2640^{e}$ & - \\
\hline 3 & Acetophenone 2 & 24 & 15 & $91^{d}$ & $1847^{e}$ & $50: 50^{d}(6: 7)$ \\
\hline 4 & $\begin{array}{l}\text { Cinnamic } \\
\text { aldehyde } \mathbf{5}\end{array}$ & 24 & 15 & $>99$ & 438 & $100(8)$ \\
\hline 5 & $\begin{array}{l}\text { Cinnamic } \\
\text { aldehyde } \mathbf{5}\end{array}$ & 4 & 15 & 56 & 245 & $100(9)$ \\
\hline 6 & Cyclohexene 3 & 1 & 15 & $>99$ & 550 & - \\
\hline 7 & Cyclohexen-2-one 4 & 24 & 15 & $>99$ & 572 & $100(10)$ \\
\hline 8 & Cyclohexen-2-one 4 & 3 & 15 & $>99$ & 572 & $100(11)$ \\
\hline
\end{tabular}

${ }^{a} 1 \mathrm{~mL}$ (7.9-10.3 mmol); reaction temp. $=75^{\circ} \mathrm{C} .{ }^{b}$ Determined by ${ }^{1} \mathrm{H}-$ NMR. ${ }^{c}$ In all five runs. ${ }^{d}$ First run. ${ }^{e}$ Total TON of 5 (toluene) or 4 (acetophenone) runs. 1,1-phenylethanol 6; 1,1-cyclohexylethanol 7; 3phenylpropanol 8, 3-phenylpropanal 9, cyclohexanol 10, cyclohexanone 11.

of different unsaturated substrates with arene, carbonyl and alkene functionalities (Table 4). Moreover, recycling experiments were performed for two aromatic substrates (Fig. 7).

For the study of nanoscale catalysts, one important factor is the surface to volume ratio of the particles. Of course one cannot exclude partial aggregation of the nanoparticles, and even topology changes, ${ }^{23}$ but the metal atoms located on the surface are accessible to interact with substrates, hence are potentially catalytically active. For the calculation of the amount of surface atoms on a nanoparticle, we estimated the volume of a spherical particle with a mean diameter of $6.9 \mathrm{~nm}$. This diameter corresponds to a particle volume of $172.0 \mathrm{~nm}^{3}$ consisting of approx. 11862 atoms. According to the magic 


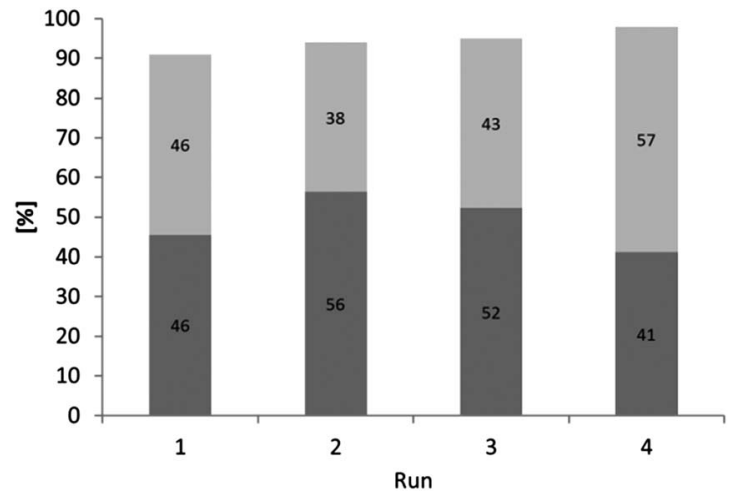

Fig. 7 Hydrogenation of acetophenone $\mathbf{2}$ in recycling runs, yielding 1-phenylethanol 8 (dark grey) and 1-cyclohexylethanol 9 (light grey).

numbers methodology as convenient tool for the evaluation of cluster formation, ${ }^{35-37}$ the number of shells is 16 and this corresponds to $\sim 18 \%$ surface atoms which are potentially active for heterogeneous catalysed reactions such as arene hydrogenation. The surface to volume ratio was used to determine the substrate catalyst ratio and TONs for the hydrogenation reactions. The Ru-NPs dispersions in ILs are stable in presence of other solvents. Therefore these IL-phases are interesting for their application in multiphase catalysis.

The hydrogenation of toluene (Table 4; entries 1 and 2) only occurred at higher pressure. This stays in contrast to previous studies with unfunctionalised ILs like $\left[\mathrm{C}_{1} \mathrm{C}_{4} \mathrm{Im}\right]\left[\mathrm{NTf}_{2}\right]$ where hydrogenation already occurred in high conversions at $\mathrm{H}_{2}$ pressures as low as 4 bar. $^{32,38}$ This observation can be related to two properties of this IL: (I) the gas solubility depends on the viscosity of the $\mathrm{IL}$, as $\left[\mathrm{C}_{1} \mathrm{C}_{1}(\mathrm{EG}) \mathrm{Im}\right]\left[\mathrm{NTf}_{2}\right]$ is a highly viscous material, higher pressures are necessary to guarantee significant amounts in the IL-phase of dissolved hydrogen. (II) Functional groups linked to the IL may act as ligands on the metal surface, and these ligands may hinder the coordination of the substrate, thus suppressing the hydrogenation of arenes, but still allowing the hydrogenation of functional groups via ligand-exchange on the surface. ${ }^{39}$ At higher pressure (40 bar) toluene was completely converted into methylcyclohexane in five runs with a total TON of $\gg 2600$, this proves the capability for recycling without significant loss of activity (entry 2).

For proving the chemo-selectivity of the catalyst phase, hence to distinguish between a suppressed hydrogenation due to gas solubility/IL-viscosity or ligand-like poisoning of the surface (see above), we used acetophenone 2 as model substrate (Table 4 ; entry 3 ). Here, we obtained a mixture of 1-phenylethanol 6 and 1-cyclohexylethanol 7 in a $\sim 1: 1$ ratio after $24 \mathrm{~h}$ in high conversions (91\%; entry 3 ). This ratio undergoes a variation in four subsequent runs during the recycling of the catalyst phase (Fig. 7).

However, one could say that there is no significant chemoselectivity for the hydrogenation of the arene moiety and the ketone. This implies that in this certain case there is no blocking of the catalyst surface by the diol of $\left[\mathrm{C}_{1} \mathrm{C}_{1}(\mathrm{EG}) \mathrm{Im}\right]$ -
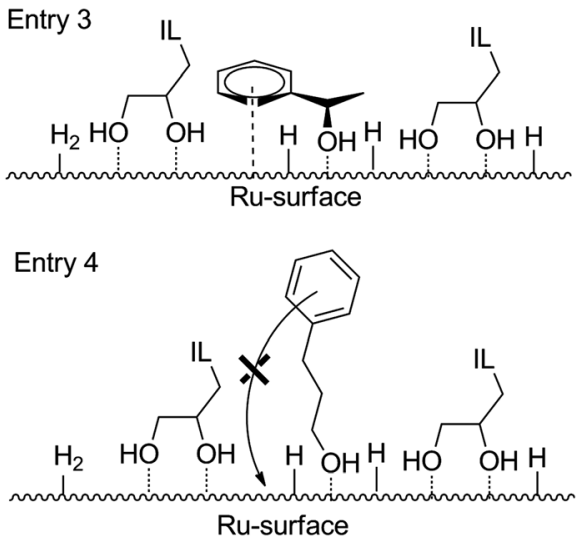

Fig. 8 Model for the coordination of intermediates/products during the hydrogenation in presence of $\left[\mathrm{C}_{1} \mathrm{C}_{1}(\mathrm{EG}) \mathrm{Im}\right]\left[\mathrm{NTf}_{2}\right]$.

$\left[\mathrm{NTf}_{2}\right]$ as surface ligand. ${ }^{39}$ Indeed, the intermediate 1-phenylethanol 8 can still coordinate as O-ligand onto the surface via ligand exchange (substrate vs. IL) which also brings the arene moiety close to the surface, hence accessible for hydrogenation (Table 4, entry 3; Fig. 8). Interestingly and contrary, the hydrogenation of cinnamic aldehyde gives under similar conditions selectively 3-phenylpropanol at high conversions (entry $4 ;>99 \%$ ), respectively 3-phenylpropanal 9 at moderate conversions (entry 5; 56\%). The aldehyde and olefin are hydrogenated subsequently and can be kinetically distinguished, but the arene remains untouched. This is again most likely due to steric aspects. During the coordination onto the surface via the oxygen, the propyl-chain acts as a spacer and the arene moiety is not accessible for hydrogenation (Fig. 8). Furthermore, we tried then to distinguish between an olefin and ketone in a hydrogenation. The hydrogenation of cyclohexene gave also quantitative conversion within one hour (Table 4; entry 6). Following, we used cyclohexen-2-one 4 which is also selectively converted into cyclohexanol $\mathbf{1 0}$ in high conversions (Table 2; entry 7; $>99 \%$ ) and at shorter reaction times cyclohexanone $\mathbf{1 1}$ is formed exclusively. Again both double bonds can be hydrogenated, similar to entry 4 , and a kinetic distinction is possible with high selectivity for the partially and fully hydrogenated products. This shows that the tested catalytic system hydrogenate olefins and aldehydes/ ketones with kinetic selectivity. Arene hydrogenation occurs effectively in absence of functional groups (entries 1 and 2), but it is slightly hindered already in presence of a neighbouring functional group (entry 3), and it can be fully blocked while incorporating a functional group via a spacer (entry 4) leading to a suppression of the arene coordination, hence, the arene moiety is not accessible for hydrogenation.

\section{Experimental}

All operations were performed in the strict absence of oxygen and water under a purified argon atmosphere using glovebox (Jacomex or MBraun) or vacuum-line techniques if not otherwise indicated. 


\section{Materials}

Mesitylcopper Cu-Mes (Nanomeps, 97\%), bis $\left(\eta^{3}-2-\right.$ methylallyl $)\left(\eta^{4}-1,5\right.$-cyclooctadiene)ruthenium $\quad \mathrm{Ru}(\mathrm{Me}-\text {-allyl })_{2}(\mathrm{COD})$ (Strem, 97\%), bis $\left(\eta^{4}-1,5\right.$-cyclooctadiene)nickel $\mathrm{Ni}(\mathrm{COD})_{2}$ (Strem), bis(trifluoromethylsulphonyl)nickel $\mathrm{Ni}\left(\mathrm{NTf}_{2}\right)_{2}$ (Solvionic), silver nitrate $\left(\mathrm{AgNO}_{3}\right)$ (ACS reagent, $\geq 99.0 \%$ ) and copper sulfate $\left(\mathrm{CuSO}_{4}\right)$ (Sigma-Aldrich) were used without further purification. ( $\eta^{4}-1,5$-Cyclooctadiene $)\left(\eta^{6}-1,3,5\right.$-cyclooctatriene)ruthenium(0) $\mathrm{Ru}(\mathrm{COD})(\mathrm{COT}), \quad$ 1-butyl-3-methylimidazolium bis(trifluoromethanesulfonimide), $\left[\mathrm{C}_{1} \mathrm{C}_{4} \mathrm{Im}\right]\left[\mathrm{NTf}_{2}\right]$ and 1-(2,3-dihydroxypropyl)-2,3-dimethylimidazolium bis(trifluoromethanesulfonimide), $\left[\mathrm{C}_{1} \mathrm{C}_{1}(\mathrm{EG}) \mathrm{Im}\right]\left[\mathrm{NTf}_{2}\right]$ have been prepared as described in literature..$^{\mathbf{4 0 - 4 2}}$

\section{General procedure for the nanoparticle synthesis}

In $1.5 \mathrm{~mL}$ of $\left[\mathrm{C}_{1} \mathrm{C}_{4} \mathrm{Im}\right]\left[\mathrm{NTf}_{2}\right]$ or $\left[\mathrm{C}_{1} \mathrm{C}_{1}(\mathrm{EG}) \mathrm{Im}\right]\left[\mathrm{NTf}_{2}\right]$ with a concentration of $0.01 \mathrm{M}$ metallic salt or organometallic precursor were mixed, then the reaction media was kept under stirring overnight. At this step if no NP formation occurred, the temperature was maintained, until a colour change appeared, successively $2 \mathrm{~h}$ at $90{ }^{\circ} \mathrm{C}$, then $4 \mathrm{~h}$ at $110{ }^{\circ} \mathrm{C}$, and finally $130{ }^{\circ} \mathrm{C}$ for $12 \mathrm{~h}$ under argon atmosphere. No reaction was claimed, when after overnight at $130{ }^{\circ} \mathrm{C}$, no colour change and no NPs in TEM images were observed. The reaction time and the results of these experiments are depicted in Table 1.

\section{General procedure for the hydrogenation reactions}

$1 \mathrm{~mL}$ of an unsaturated substrate (see Table 2) was added to ruthenium nanoparticles in $\left[\mathrm{C}_{1} \mathrm{C}_{1}(\mathrm{EG}) \mathrm{Im}\right]\left[\mathrm{NTf}_{2}\right]$ (see above; $1 \mathrm{~mL}$ IL) on air in a screw-capped vial with a septa and needle. The vial was placed in a stainless reactor and heated to $75{ }^{\circ} \mathrm{C}$ and pressurised with hydrogen (pressure see Table 2). After the indicated reaction time (Table 2), the autoclave was cooled to room temperature, the pressure was carefully released and an aliquot was analysed by ${ }^{1} \mathrm{H}-\mathrm{NMR}$ in $\mathrm{C}_{6} \mathrm{D}_{6}$.

For the recycling, the IL-layer was extracted with pentane or ether (at least three times), the catalyst-/IL-phase was dried under reduced pressure and then the pure catalyst-/IL-phase was charged with substrate again.

\section{Characterization}

The Cu-, Ni-, Ru- and Ag-NP sizes were determined by transmission electron microscopy (TEM) on a Philips CM120 $(120 \mathrm{keV})$, and the structure of the nanoparticles were examined using a Jeol-2010 transmission electron microscope (TEM) operated at a $200 \mathrm{kV}$ acceleration voltage. TEM and HRTEM samples were prepared by dropping the IL solution onto a copper TEM grid with amorphous carbon over layers, followed by the removal of excess amounts of solution with filter paper. The preparation is stored in pill-box filled with argon and taken from the glove box only right before the analysis. ${ }^{1} \mathrm{H}$ - and ${ }^{13} \mathrm{C}-\mathrm{NMR}$ spectra were recorded on a $300 \mathrm{MHz}$ Bruker, with $\mathrm{C}_{6} \mathrm{D}_{6}, \mathrm{CD}_{2} \mathrm{Cl}_{2}$ or $\mathrm{d}_{6}$-DMSO as external reference.

\section{Conclusions}

In unfunctionalized $\mathrm{C}_{1} \mathrm{C}_{4} \operatorname{ImNTf}_{2}$ no formation of NP was observed under heating in absence of a reductive agent with $\mathrm{Ag}^{\mathrm{I}} \mathrm{NO}_{3}, \mathrm{Cu}^{\mathrm{II}} \mathrm{SO}_{4}, \mathrm{Cu}^{\mathrm{I}} \mathrm{Mes}, \mathrm{Ni}^{\mathrm{II}}\left(\mathrm{NTf}_{2}\right)_{2}$, and $\mathrm{Ru}^{\mathrm{O}}$ (COD)(COT). In the dihydroxyl IL $\mathrm{C}_{1} \mathrm{C}_{1}$ (EG)ImNTf $\mathrm{Im}_{2}$ the synthesis of M-NPs $(\mathrm{M}=$ $\mathrm{Cu}, \mathrm{Ag}$ ) from $\mathrm{Ag}^{\mathrm{I}} \mathrm{NO}_{3}$ and $\mathrm{Cu}^{\mathrm{I}}$ Mes occurred through the oxidation of hydroxyl functionality. With $\mathrm{Ni}^{\circ}(\mathrm{COD})_{2}$ and $\left[\mathrm{Ru}^{\mathrm{II}}\right.$ (COD)(2-methylallyl $)_{2}$ ], Ni-NPs and Ru-NPs were formed due to the activation of the acidic protons on the imidazolium ring. For all these in situ NP syntheses the $\left[\mathrm{C}_{1} \mathrm{C}_{1}(\mathrm{EG}) \mathrm{Im}\right]\left[\mathrm{NTf}_{2}\right]$ is simultaneously solvent, stabilizer and reductive agent. The catalytic hydrogenation with $\mathrm{Ru}$ nanoparticles in $\left[\mathrm{C}_{1} \mathrm{C}_{1}(\mathrm{EG}) \mathrm{Im}\right]\left[\mathrm{NTf}_{2}\right]$ showed that it is possible to hydrogenate effectively arenes only in absence of functional groups. And, the arene hydrogenation is completely blocked by incorporation of a functional group via a spacer. In this case only alkenes and aldehydes are accessible for hydrogenation via a ligand exchange reaction. Pointing out, that hydrogenation of alkenes is possible while aldehydes and ketones remain untouched.

\section{Acknowledgements}

We acknowledge the Ministerium für Innovation, Wissenschaft und Forschung NRW (MIWF-NRW) for financial support within the Energy Research Program for the Scientist Returnee Award (NRW-Rückkehrerprogramm) for Dr M. H. G. Prechtl. Moreover, C. Gedig is thankful for helpful discussions with Sebastian Sahler and Michael T. Keßler. The HRTEM images were carried out by Dr Philippe Arquillière to whom we are thankful.

\section{Notes and references}

1 D. Astruc, F. Lu and J. R. Aranzaes, Angew. Chem., Int. Ed., 2005, 44, 7852-7872.

2 J. D. Scholten, B. C. Leal and J. Dupont, ACS Catal., 2012, 2, 184-200.

3 M. H. G. Prechtl, J. D. Scholten and J. Dupont, Molecules, 2010, 15, 3441-3461.

4 P. Arquilliere, P. H. Haumesser and C. C. Santini, Microelectron. Eng., 2012, 92, 149-151.

5 A. Umer, S. Naveed, N. Ramzan and M. S. Rafique, NANO, 2012, 7(5), 1230005.

6 F. Y. Cheng and J. Chen, Chem. Soc. Rev., 2012, 41, 21722192.

7 P. Lignier, R. Bellabarba and R. P. Tooze, Chem. Soc. Rev., 2012, 41, 1708-1720.

8 D. S. Wang and Y. D. Li, Adv. Mater., 2011, 23, 1044-1060.

9 S. Magdassi, M. Grouchko and A. Kamyshny, Materials, 2010, 3, 4626-4638.

10 G. Konstantatos and E. H. Sargent, Nat. Nanotechnol., 2010, 5, 391-400.

11 R. Venkatesan, M. H. G. Prechtl, J. D. Scholten, R. P. Pezzi, G. Machado and J. Dupont, J. Mater. Chem., 2011, 21, 3030-3036.

12 M. Valden, X. Lai and D. W. Goodman, Science, 1998, 281, 1647. 
13 A. T. Bell, Science, 2003, 299, 1688-1691.

14 G. Schmid, Nanoparticles: From Theory to Application, WileyVCH, Weinheim, 2004.

15 G. A. Somorjai and J. Y. Park, Top. Catal., 2008, 49, 126-135.

16 D. Astruc, Nanoparticles and Catalysis, Wiley-VCH, Weinheim, 2008.

$17 \mathrm{H}$. Boennemann and K. S. Nagabhushana, in Metal Nanoclusters in Catalysis and Materials Science: The Issue of Size Control, ed. B. Corain, G. Schmid and N. Toshima, Elsevier B.V., Amsterdam, 2008, pp. 21-48.

18 S. H. Joo, J. Y. Park, J. R. Renzas, D. R. Butcher, W. Y. Huang and G. A. Somorjai, Nano Lett., 2010, 10, 2709-2713.

19 B. Chaudret, Top. Organomet. Chem., 2005, 16, 233-259.

20 B. Chaudret and K. Philippot, Oil Gas Sci. Technol., 2007, 62, 799-817.

21 T. Welton, Chem. Rev., 1999, 99, 2071-2083.

$22 \mathrm{P}$. Wasserscheid and T. Welton, Ionic liquids in synthesis, Wiley-VCH, Weinheim, 2008.

23 J. Dupont and J. D. Scholten, Chem. Soc. Rev., 2010, 39, 17801804.

24 J. P. Hallett and T. Welton, Chem. Rev., 2011, 111, 3508-3576.

25 J. Dupont, G. S. Fonseca, A. P. Umpierre, P. F. P. Fichtner and S. R. Teixeira, J. Am. Chem. Soc., 2002, 124, 4228-4229.

26 T. Y. Kim, W. J. Kim, S. H. Hong, J. E. Kim and K. S. Suh, Angew. Chem., Int. Ed., 2009, 48, 3806-3809.

27 H. J. Ryu, L. Sanchez, H. A. Keul, A. Raj and M. R. Bockstaller, Angew. Chem., Int. Ed., 2008, 47, 7639-7643.

28 M. Dewan, A. Kumar, A. Saxena, A. De and S. Mozumdar, PLoS One, 2012, 7, e29131.
29 L. Zhao, C. Y. Zhang, L. Zhuo, Y. G. Zhang and J. Y. Ying, J. Am. Chem. Soc., 2008, 130, 12586-12587.

30 Y. Gao, A. Voigt, M. Zhou and K. Sundmacher, Eur. J. Inorg. Chem., 2008, 3769-3775.

31 D. Dorjnamjin, M. Ariunaa and Y. K. Shim, Int. J. Mol. Sci., 2008, 9, 807-820.

32 M. H. G. Prechtl, P. S. Campbell, J. D. Scholten, G. B. Fraser, G. Machado, C. C. Santini, J. Dupont and Y. Chauvin, Nanoscale, 2010, 2, 2601-2606.

33 L. L. Lazarus, C. T. Riche, N. Malmstadt and R. L. Brutchey, Langmuir, 2012, 28, 15987-15993.

34 S. Gruendemann, A. Kovacevic, M. Albrecht, J. W. Faller Robert and H. Crabtree, Chem. Commun., 2001, 2274-2275.

35 A. P. Umpierre, E. de Jesus and J. Dupont, ChemCatChem, 2011, 3, 1413-1418.

36 K. S. Weddle, J. D. Aiken and R. G. Finke, J. Am. Chem. Soc., 1998, 120, 5653-5666.

37 B. K. Teo and N. J. A. Sloane, Inorg. Chem., 1985, 24, 4545-4558.

38 M. H. G. Prechtl, M. Scariot, J. D. Scholten, G. Machado, S. R. Teixeira and J. Dupont, Inorg. Chem., 2008, 47, 89959001.

39 M. H. G. Prechtl, J. D. Scholten and J. Dupont, J. Mol. Catal. A: Chem., 2009, 313, 74-78.

40 P. Pertici, G. Vitulli, M. Paci and L. Porri, Dalton Trans., 1980, 1961-1964.

41 L. Magna, Y. Chauvin, G. P. Niccolai and J.-M. Basset, Organometallics, 2003, 22, 4418-4425.

42 A. L. Lafarate, J. E. Bara, D. L. Gin and R. D. Noble, Ind. Eng. Chem. Res., 2009, 48, 8757-8756. 